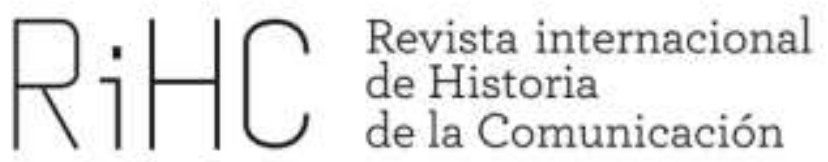

\title{
LA PROPAGANDA COMO ARMA DE GUERRA EN LA REVOLUCIÓN MEXICANA. LAS BATALLAS DEL BAJÍO (1915)
}

DOI: http://dx.doi.org/10.12795/RiHC.2016.i07.04

Francisco Iván Méndez Lara

Posgrado en Historia, Universidad Nacional Autónoma de México Ivan.mendez.lara@gmail.com

Recibido: 9-9-2016

Aceptado: 2-12-2016

Resumen: La Revolución mexicana y sus batallas más significativas tuvieron otra cara que no ha sido lo suficientemente estudiada por la historiografía: la propaganda a través de la prensa. Este trabajo explica el proceso de "construcción" de los hechos de armas ocurridos en el Bajío durante la "guerra de facciones" entre abril y julio de 1915. A través de los artículos y editoriales de los órganos informativos de las distintas facciones se demostrará la relevancia que tuvieron los impresos como generadores de espacios de discusión y legitimación.

Palabras clave: Revolución mexicana, propaganda, prensa

Abstract: The Mexican Revolution and their most significant battles had another face that has not been sufficiently studied by the historiography: the propaganda through the press. This work explains the process of "war facts construction" happened in the Bajio during the "guerra de facciones", between April and July of 1915. Through articles 
and editorials in revolutionary newspapers, the relevance of newspapers as discussion and legitimacy spaces will be demonstrated.

Keywords: Mexican revolution, propaganda, press

\section{Introducción ${ }^{1}$}

Después del triunfo frente a Victoriano Huerta - general que había detentado el poder tras el asesinato de Francisco I. Madero en 1913- las fuerzas ganadoras lideradas por Venustiano Carranza y Pancho Villa entraron en un conflicto irremediable que dio paso a una nueva etapa dentro de la Revolución mexicana conocida como la "guerra de facciones" (1914-1915). A pesar de los diversos intentos de reconociliación llevados a cabo en la Convención revolucionaria, primero en la ciudad de México y luego en Aguascalientes, la reunificación fue imposible.

En diciembre de 1914 los bandos en pugna se encontraban prácticamente en condiciones equitativas. La supremacía de los convencionistas (conformados por los villistas, los zapatistas y un tercer sector más independiente) sobre los carrancistas al inicio de la lucha armada - debido a que gran parte del territorio nacional estaba bajo su dominio y contaba con líneas de comunicación ininterrumpidas desde la frontera con Estados Unidos hasta Morelos - fue temporal. (Katz, 2000: t. II, 14-15) "La ventaja de los convencionistas se desvanecía y revertía en el mediano plazo por varias razones más económicas y políticas que militares. En primer lugar, no había unidad de mando en el bando convencionista. En segundo lugar, no es que carecieran del todo de un proyecto alterno al constitucionalismo, sino que éste, en embrión, se iría construyendo a lo largo de 1915."(Salmerón, 2008: 109). En tercer lugar, con el transcurrir de los meses los recursos villistas se agotaron: la dificultad para conseguir municiones se incrementó, el ganado de las haciendas confiscadas era prácticamente inexistente, y la producción algodonera disminuyó. (Quirk, 1962: 164). Al mismo tiempo Carranza y sus hombres más cercanos se posicionaron en las zonas económicamente más importantes como el puerto de Veracruz, Merida, Progreso y la región petrolera de El Ébano, además controlaron las exportaciones de los campos henequeneros de Yucatán y las regiones cafetaleras de Chiapas.

El mismo proceso ocurrió con los dos personajes más relevantes de ese momento, Pancho Villa y Venustiano Carranza, el primero contó con mayor carisma en el interior y en el exterior del país hasta principios de 1915, en octubre del mismo año, cuando la guerra había concluido, la situación dio un viraje favorable para Venustiano Carranza.

\footnotetext{
${ }^{1}$ Agradezco a la Dra. Georgette José su apoyo incondicional a lo largo de toda mi formación como historiador. Asimismo agradezco el impulso que, día tras día, me brinda Karina Villegas Terán.
} 
Paralelamente, el periodismo faccionario de la época se dedicó a consolidar un par de interpretaciones de la lucha armada que se desarrollaba en gran parte de territorio mexicano. Este trabajo analizará la "construcción" de los enfrentamientos militares entre villistas y carrancistas en la región del Bajío con el objetivo de demostrar la forma en que la prensa y la propaganda desempeñaron un papel fundamental en las estrategias de los distintos bloques revolucionarios. En pocas palabras, detrás de la lucha armada, se desarrolló un combate de impresos, una guerra de papel.

\section{Prensa y propaganda durante la "guerra de facciones"}

La propaganda es un fenómeno existente desde la antigüedad, pasando por la Edad Media y la época Moderna, sin embargo, las dos Guerras Mundiales, la Guerra Civil Española y la Guerra Fría dejaron clara su relevancia como uno de los elementos fundamentales en procesos militares. El complejo sistema propagandístico de la Alemania nazi, del fascismo italiano, de la Rusia soviética, son sólo algunos de los ejemplos más conocidos. No obstante, pese al desarrollo de las tecnologías (radio, televisión, internet), muchas de las estrategias de propaganda han cambiado poco, la omisión informativa, la creación de enemigos, la legitimación de movimentos militares a través del sentimentalismo, son categorías que han atravesado los siglos y se mantienen vigentes. El uso y el desuso de la propaganda por parte de los hombres que detentaron el poder y lideraron guerras fueron innegables. El siglo XX concluyó con luchas discursivas dentro de procesos bélicos, las guerras en Irak y Afganistán fueron los casos más relevantes en todos los aspectos. Actualmente continúa siendo un tema común en el mundo, cuestión que hace necesaria su revisión y comprensión en distintas etapas y latitudes.

El caso mexicano no es una excepción. La propaganda a través de la prensa fue una constante, principalmente desde el inicio de la Revolucion de 1910. Las luchas decimonónicas entre los diversos proyectos de nación (federalistas, centralistas, conservadores...), encontraron en las páginas de los diarios el medio necesario para difundir sus ideas políticas. La guerra entre México y Estados Unidos (1846-1848) fue uno de los primeros enfrentamientos propagandísticos que mayor cobertura periodística tuvieron. El vínculo de la prensa con los múltiples presidentes en turno fue una regularidad, basta recordar la creación del periódico El Imparcial durante la presidencia de Porfirio Díaz cuyo objetivo fue terminar con la prensa ideologizada, poner énfasis a la nota roja y de la vida cotidiana a un bajo costo. 
Durante la Revolución mexicana, desde Francisco I. Madero hasta Álvaro Obregón, los líderes contaron con periódicos aliados. Incluso el caso de Madero resultó paradigmático para la historia de la prensa mexicana, ya que a través de propaganda contraria a su gobierno, principalmente a lo largo de 1912, los periódicos mermaron la de por sí inestable presidencia del coahuilense. Venustiano Carranza comprendió que no podía cometer los mismos errores que el presidente asesinado, por lo que puso especial atención en el uso de la prensa como propaganda.

En el caso particular del periodo 1914-1915, la guerra, la prensa y la propaganda estuvieron íntimamente relacionadas. Es importante remarcar que ese mismo triángulo tuvo mucho que ver con la forma en que habría de escribirse la historia posterior a los hechos militares acaecidos en esos años. Es decir, la "historia de los vencedores" tomó mucho de lo que se escribió al calor de los acontecimientos, de lo que Álvaro Matute denomina como la "historiografía inmediata", es decir, de lo publicado en la prensa.

A lo largo de los primeros seis meses de 1915, los diarios faccionarios aseguraron que cada enfrentamiento había culminado con un triunfo de su propio bando. Tanto en EI Pueblo y El Demócrata, órganos informativos carrancistas, como en La Convención, favorable al villismo y al zapatismo, se procuró mostrar que sus ejércitos eran los mejores y los que habrían de ganar la guerra.

Actualmente ha comenzado una suerte de revisionismo historiográfico de este periodo, en donde se busca dejar de lado la idea de que la "guerra de facciones" -e incluso la revolución - se definió en los campos del Bajío y que Villa perdió por carecer de conocimientos bélicos, sino que el triunfo carrancista se definió por múltiples factores militares (Salmerón, 2015), pero también políticos y económicos. La historia, pues, debe reescribirse y el análisis hemerográfico devela con mayor claridad la manera en que la propia versión histórica de los hechos se ha constituido. La propaganda constitucionalista ha sido trabajada poco, en comparación con otros tópicos revolucionarios, Figueroa Daza (2010) ofrece un análisis global de los canales y mensajes propagandísticos existentes en la prensa subvencionada por Venustiano Carranza. No obstante, el autor no se detiene en el análisis de la prensa en los momentos trascendentales de las batallas en el Bajío. Caso similar al de Anderson (2010) quien se enfocó a analizar la transformación de la imagen que se tenía de Pancho Villa en Estados Unidos.

La revisión y el análisis de los periódicos, día a día, permite entender por qué y cómo la información se modificó cotidianamente, no sólo por las labores de propaganda, sino también por las dificultades comunicativas. Las páginas de El Pueblo, El Demócrata y La Convención deben ser vistas de forma crítica para horadar entre sus líneas la consolidación de discursos facciosos y no ser tomadas como la "verdad" de los sucesos, sino como una forma de entender y legitimar un par de proyectos 
revolucionarios en una coyuntura de violencia continua y vacío de poder. La prensa vista como fuente y objeto de estudio brinda otros panoramas para el análisis de un momento histórico específico.

Durante la "guerra de facciones", los periódicos se convirtieron en órganos propagandísticos. En la conformación de toda campaña de propaganda se lleva a cabo un proceso de selección de información que favorezca al bando que representa el impreso ("la presentación de los hechos" u "omisión selectiva"), recoger toda la información posible de un asunto en específico y exaltar los puntos a su favor, son factores imprescindibles en los momentos de guerra. "El éxito o fallo en conseguir una reacción favorable de la audiencia dependerá de la selección de hechos y de la presentación de los mismos, procurando siempre presentarlos en comparación con los del enemigo." (Domenach, 1962:114)

El desarrollo de la propaganda de guerra se consolidó en el siglo Xx, tres fueron los principales factores: el aumento de la población mundial, el desarrollo de tecnologías comunicativas, sobre todo de la prensa escrita que dejó de ser paulatinamente exclusiva de las élites para comenzar a distribuirse entre todos los estratos (prensa moderna) y, finalmente, con el desarrollo de movimientos de masas, la ideología desempeñó un papel central en la justificación de las acciones políticas y bélicas (Bobbio, 1982: v. II, 1333-1336). Dentro de ésta, se pueden estudiar múltiples factores que inciden en el proceso comunicativo, de los cuales pueden analizarse los siguientes: el emisor, es decir, "la organización encargada de elaborar y difundir mensajes de propaganda;" el medio o los canales a través de los que se difunden los mensajes; los contenidos y estrategias de los propios escritos, y "los efectos o repercusión de ese fenómeno propagandístico" (Pizarroso, 1999: 159) Este texto pondrá acento a la revisión del emisor, al medio por el que se distribuye el mensaje (los periódicos) y a los contenidos de sus publicaciones.

Nos enfocaremos dentro del mensaje periodístico, tomando en cuenta que las estrategias propagandísticas casi siempre se entrelazan unas con otras, al análisis de dos aspectos:

a) Construcción del enemigo. Se ubica y se establece un enemigo común, pues no se pelea contra un grupo, sino contra un personaje definido (Villa, Zapata, Carranza, Obregón). Esta "construcción" suele sustentarse en elementos maniqueos, el desprestigio se logra mediante la anexión de ciertos valores que el público al que va dirigida la propaganda odia o teme.

b) Exageración, omisión y deformación. Las noticias favorables se engrandecen o se descartan, según las necesidades del momento. Los rumores y las mentiras son elementos comunes de esta estrategia propagandística (Domenach, 1962: 67). 
Estos procedimientos fueron fundamentales en el relato de las campañas militares durante la Revolución mexicana, principalmente en las que ocurrieron en el Bajío, primero en Celaya y poco después en la estación ferroviaria de Trinidad. La exageración y la manipulación de lo ocurrido fueron las armas de las que se valió la prensa, unos para demostrar su superioridad, otros para hacer creer que aún tenían posibilidades de triunfar.

\section{2 "Elaborando y reelaborando" las campañas militares}

\subsection{Celaya y la construcción del enemigo}

Una vez conformados los bandos en pugna a finales de 1914, los convencionistas y los carrancistas entraron a una etapa de complejos enfrentamientos en el Bajío mexicano, Celaya, la estación ferroviaria de Trinidad y Aguascalientes fueron los puntos principales donde combatieron los hombres de Pancho Villa vs los de Álvaro Obregon.

Los partes de guerra de la primera batalla en Celaya, Guanajuato (4-6 de abril de 1915) del general Álvaro Obregón, fueron reproducidos en El Pueblo (aunque se trataron de resúmenes de los que más tarde aparecieron anexados en su libro Ocho mil kilómetros en campaña) y dieron por sentado que la "reacción villista" había sido aniquilada. El periódico carrancista aseguró que las poderosas cargas de caballería de Pncho Villa, sin ningún planteamiento táctico (sin dejar reservas), fueron detenidas por Obregón que, tras poner un fuerte dispositivo defensivo, esperó a que las huestes del norte se desgastaran $\mathrm{y}$, finalmente, pudieran atacar por la retaguardia. El Pueblo, en un encabezado, aseguró:

\footnotetext{
"Triunfó el ejército constitucionalista en la ciudad de Celaya contra la reacción" Cuarenta cargas de caballería no sólo resistieron los patriotas, sino que las rechazaron ungidos por la gloria...

Más de mil muertos y un número considerable de heridos fueron encontrados sobre el campo adversario, lo que demuestra muy a las claras que se empeñan todas las energías del triunfo
} 
Villa dirigia la accion, afortunadamente. ${ }^{2}$

De la misma forma, El Demócrata, difundió el triunfo "arrollador" de los carrancistas, "3,000 reaccionarios perdió Villa en el formidable combate que entablara con las Fuerzas del Gral. Álvaro Obregón en las inmediaciones de Celaya", en este caso el diario dirigido por Rafael Martínez "Rip-Rip", antiguo maderista y aliado del Primer Jefe, aseguró que Pancho Villa había sido el primero en huir, dejando abandonados a sus hombres. ${ }^{3}$ Por otro lado, el periódico La Convención ni siquiera era publicado debido al continuo cambio de sede del grupo convencionista.

Entre el primer y el segundo enfrentamiento en Celaya (13-15 de abril), la prensa carrancista se dedicó a impulsar una campaña de exaltación en torno a los hechos de armas acaecidos en dicho sitio. El nueve de abril se publicó la nota editorial "La Justicia está con nosotros. Sobre la victoria de Ayer" en donde se elevó a Celaya como una "promesa de redención para la humanidad", además de subrayar el hecho de que no se estaba venciendo a Villa, sino al alma de la burguesía, de la Iglesia, de los yankees, se estaba destruyendo a los últimos baluartes de la reacción misma. El triunfo era del pueblo, de Carranza para el pueblo a través del ejército constitucionalista, al cual le pertenecía la "Justicia," ${ }^{4}$ mientras que con Villa, huían no sólo sus hombres, sino también más de cien curas.

Días después El Pueblo publicó el informe de un "joven y estimable teniente del ejército constitucionalista", de quien no se dio el nombre, en el que narraba la acción en la primera asonada de Celaya, destacó el actuar de un "párvulo trompetita" que con su melodía despistó a los villistas y contribuyó a su huída: "Obregón consideró que Villa volvería a pretender otro ataque, pero con asombro vieron que Villa y su brillante Estado Mayor, abandonando artillería y heridos, laureles y fama en los campos de Celaya, emprendió la huída, llevándose unos cuantos cañones y los heridos que tuvieron más a la mano." ${ }^{5}$ Villa no sólo era un mal militar, sino también era cobarde para los carrancistas.

En la misma sintonía el 11 de abril se publicó un editorial que desprestigiaba a los convencionistas, principalmente al "perdedor" en Celaya, en la que se pueden analizar perfectamente la construcción del enemigo - proceso iniciado desde finales del año anterior, pero utilizado con gran insistencia durante las campañas militares- y la exageración de los hechos durante las batallas:

\footnotetext{
2 “Triunfó el ejercito constitucionalista...", El Pueblo, 8 de abril de 1915, p. 1.

3 “Extra”, El Demócrata, 8 de abril de 1915, p. 1.

4 "La Justicia está con nosotros. Sobre la victoria de Ayer", El Pueblo, 9 de abril de 1915, p. 3.

5 “Cómo fue la acción de armas en Celaya", El Pueblo, 8 de mayo de 1915, p. 5.
} 
Yo he visto alguna vez caer un tigre herido, al fondo de un barranco, en su precipitado descenso, ramajes, piedras, hojarasca y polvo en torbellino turbulento; algún momento lo ví sostenerse, y ya parecía que lograba rehacerse, cuando la rama a que asido se quedara desgajándose rápida, precipitó al animal hacia el profundo abismo.

El villismo, presentado como un "tigre herido" comenzaba su descenso; los principales enemigos del estado liberal mexicano decimonónico "el clericalismo, el cientificismo y exfederalismo" eran obstáculos que sucumbirían definitivamente con él. ${ }^{6}$ En las páginas de los diarios carrancistas, Villa y sus hombres eran aliados de los contrarrevolucionarios. El pueblo y la justicia estaban con Carranza, la reacción - según los periódicos carrancistas - no podía seguir negando el arrollador triunfo de la causa movida por "ideales sinceros" del Primer Jefe.

Un segundo ataque se dio en la misma población del Bajío del 13 al 15 de abril, pero en esta ocasión Obregón se había reforzado con unos 15000 hombres (Obregón, 1960: 327), mientras Villa fue fortalecido por fuerzas provenientes del norte y algunos contingentes de Michoacán, Jalisco y San Luis Potosí. Una vez más la estrategia de Obregón consistió en formar un círculo defensivo alrededor de la plaza de Celaya y, con las reservas que había dejado fuera de la misma, atacó a los villistas cuando se habían agotado para así obtener un nuevo triunfo.

La prensa carrancista, narró las acciones del general Álvaro Obregón, quien conocía los planes del "traidor" Villa y permaneció a la expectativa hasta el trece de abril, cuando al ser atacado inició la ofensiva y el combate se generalizó en una línea de veinte kilómetros, se extendió hasta alcanzar doscientos kilómetros cuadrados. Los dragones villistas, "como de costumbre", hicieron "formidables" cargas de caballería sobre las posiciones de los revolucionarios; pero en todos sus asaltos fueron rechazados con energía. "Así permanecieron nuestras fuerzas, hasta que por órdenes del General Obregón, tomaron la ofensiva, que dio por resultado que fuesen derrotados los traidores ayer, a la una y media de la tarde, saliendo violentamente la caballería para perseguirlos y capturarle los trenes con impedimento que pudieron sacar del campo de la lucha." "7 Aseguró el parte de guerra reproducido en El Pueblo.

El resultado fue una victoria "arrolladora" de los obregonistas el día 15 de abril de 1915 después de que las caballerías de Cesáreo Castro - por el flanco izquierdo- y Joaquín Amaro - por el derecho- atacaron al bando de Villa. "Al grito de 'sálvese quien pueda' huyeron del campo de batalla los veteranos de la antigua División del Norte", "los leones, se habían convertido en "mansos corderos." (Barragán, 1985: 295296). Este triunfo "genial” de Obregón -en palabras de Juan Barragán- demostró que

\footnotetext{
${ }^{6}$ A.P.R., "En el campo villista tocan a muerte", El Pueblo, 11 de abril de 1915, p. 3.

7 “Ha triunfado el Ejército Constitucionalista”, El Pueblo, 16 de abril de 1915, p. 1.
} 
los villistas, con una estrategia débil y "sin ideales justos y buenos", se encaminaban a la derrota.

El encabezado de El Pueblo, del 16 de abril de 1915, fue: "Envuelto en los fulgores de la gloria, el estandarte de la legalidad ondea orgulloso sobre las trincheras de la nefanda reacción," en la nota se subrayaron las palabras de Carranza, quien vio en este triunfo la derrota de la "reacción", además de exagerar notablemente las bajas y heridos del bando villista, las cuales calcularon en 14 000. El Primer Jefe felicitó a sus hombres, quienes "arrollando ayer a Huerta y hoy a Villa", marcaron en las "páginas gloriosas de la historia que los hombres honrados y los principios sanos siempre triunfarán, a pesar de la fuerza y el oro." ${ }^{8}$ Dicha victoria se mostró como resultado de la unión del "vengador de la justicia" Venustiano Carranza con el "campeón" Obregón. Obviamente, dicha prensa no mencionó la forma en que el general Dionisio Triana que comandaba una de las brigadas de infantería villista dejó el paso libre a las infanterías carrancistas (Calzadíaz, 1967: t. II, 210).

El periódico de la Convención Revolucionaria reapareció el lunes 26 de abril. ${ }^{9}$ En la página dos, su director, Heriberto Frías - autor de la obra Tomochic-, llamaba a los revolucionarios "equivocados" para que se pasaran al bando que verdaderamente velaba por el triunfo de la revolución: "la Convención no les cerrará las puertas a los revolucionarios que de buena fe hayan huido hacia el carrancismo personalista. La Convención hace obra de paz y obra de unión." ${ }^{10}$ Los convencionistas y su prensa mostraron notorios rasgos de debilidad propgandística al tratar de acercarse al enemigo que los estaba derrotando en los campos de batalla.

Promesas de mejoras sociales aparecieron un día después en el periódico convencionista, aseguraba que con los fondos con los que aún contaba, la revolución:

Procederá de abajo hacia arriba, comenzando por dar medios de vida y libertad al campesino y al obrero, los hará dueños de una parcela de tierra mexicana para que se sientan realmente mexicanos; los llamará a que formen el Ayuntamiento libre escuela de democracia, base y sostén de las instituciones libres; hará que integren el ejército nacional para que por sí mismos guarden sus conquistas. Por otra parte, devolverá sus tierras al indio despojado, le pondrá maestros de escuela y le ofrecerá con un jornal más alto una existencia con mayores

\footnotetext{
8 “Envuelto en los fulgores de la gloria...", El Pueblo, 16 de abril de 1915, p. 1.

${ }^{9}$ El periódico desapareció debido a los constantes cambios de sede de la Convención. En la última semana de enero de 1915 se trasladaron a Cuernavaca, Morelos. Al iniciar marzo la junta de revolucionarios regresó a la ciudad de México, pero debido a las acciones de Obregón en su paso por la metrópoli (enero-marzo), que incluyó la destrucción y saqueo de las instalaciones periodísticas de la Convención, fue imposible que se continuara publicando La Convención desde mediados de marzo.

${ }^{10} \mathrm{H}$. Frías, "La Paz digna, después de la guerra. La Convención no es Academia sino crisol", La Convención, 26 de abril de 1915, p. 3.
} 
aspiraciones para que acabe de despertar de su sueño de siglos y entre a la lucha, al trabajo, a la vida. ${ }^{11}$

La Revolución aún existía debido a que sólo con el triunfo de las libertades del pueblo ésta tocaría su fin. ${ }^{12}$ Sin embargo, de las batallas ocurridas en Celaya nada se dijo, el silencio fue una estrategia convencionista: la omisión servía mucho más en este caso, puesto que no había forma de refutar el triunfo del carrancismo en los primeros días de reaparición de los órganos informativos convencionistas.

Por aquéllos días la prensa carrancista se dio a la tarea de fomentar rumores sobre la división y pelea entre los miembros del bando villista. El 13 de mayo se aseguró que el general Felipe Ángeles - uno de los militares más importantes de la División del Norte-era prisionero de Pancho Villa ${ }^{13}$ y días más tarde se afirmó también que el propio Ángeles había abandonado a Villa para dirigirse a Matamoros. Junto a ello, se aseguró que algunas "bandas" de exfederales-huertistas se estaban formando en Estados Unidos para penetrar el territorio mexicano, la prensa aseveró que estos hombres recibían su salario de los bolsillos de los científicos que vivían en el país vecino desde la caída de Victoriano Huerta. Junto al repliegue villista ante los ataques de Obregón, El Pueblo insistió en que los ejércitos pagados por la "reacción" habían cruzado la frontera y ya se encontraban peleando, pero no contra la "Revolución" del Primer Jefe, sino contra los propios villistas, de ahí que parte de la primera plana del 18 de mayo asegurara que "Los científicos después de tomar por instrumento a Villa, vuelven sus armas contra él." ${ }^{14}$

El objetivo era claro: demostrar que los enemigos se enfrentaron entre sí, mientras Carranza y los suyos ganaban terreno e incrementaban su moral. ${ }^{15}$ La dinámica de desprestigio del enemigo cobró un peso fundamental en la intentona de la prensa carrancista para buscar la supremacía frente a los villistas durante la etapa más álgida de la lucha armada. Notas editoriales como "La agonía de los científicos", "La lógica del triunfo constitucionalista", "El fracaso final", "La austeridad frente al pillaje", son ejemplos notables de dicha labor. Como se ha visto, la constante fue mostrar a Villa como el último reducto reaccionario quien, al final, los llevó al fracaso dada su ineficacia. La prensa pro-Carranza se empecinó en comparar a Villa con Porfirio Díaz y Victoriano Huerta, pero la bandera carrancista los estaba aniquilando, ${ }^{16}$ en otras

\footnotetext{
${ }^{11}$ Luis Coyula, “Cuál es la paz que busca la Revolución”, La Convención, 27 de abril de 1915, p. 2.

12 R.E.M., “La revolución debe llegar hasta el fin”, La Convención, 3 de mayo de 1915, p. 2.

13 "Se asegura que Ángeles es prisionero de Villa", El Pueblo, 13 de mayo de 1915, p. 1.

14 "Los científicos después de tomar por instrumento a Villa, vuelven sus armas contra él", El Pueblo, Veracruz, martes 18 de mayo de 1915, p. 1.

15 "Los villistas se repliegan a Aguascalientes", en El Pueblo, Veracruz, martes 18 de mayo de 1915, p. 1.

16 "La agonía de los científicos", El Pueblo, 13 de mayo de 1915, p. 3.
} 
palabras: la reacción, cuya marioneta y máximo representante era Francisco Villa, estaba a punto de desaparecer.

La causa "vandálica villista" había cavado su tumba, en palabras de la prensa proCarranza, su poderío sólo podía ser temporal debido a que era el "Dios del crimen" quien los ayudaba. Villa, en esta etapa de la propaganda carrancista, era mostrado como el más bajo organismo existente sobre la faz de la tierra. Los triunfos en el Bajío les dio la pauta para desprestigiarlo de manera mordaz, comparándolo con un tigre herido después de sus derrotas frente a Obregón: "Doroteo Arango (a) Pancho Villa, el "indomable Atila del Norte" o el "Napoleón Bandido" como se le llamó, había comprendido "su miserable organismo microbiano". Al efecto, Álvaro Obregón, ese "ilustre" general constitucionalista que lleva "en sus venas la brava sangre yaqui, tuvo a bien sacudirse el polvo de su casaca con la hirsuta melena de la testa del nunca bien ponderado Doroteo Arango." ${ }^{17}$ Cuando comenzó a perder en el Bajío, "Doroteo vio entonces su pequeñez espantosa. Sintió sed de sangre y se lanzó a la batalla, pero ni para beber sana roja, por las heridas abiertas de los enemigos, sino para llorar como mujer cobarde e impotente ante el domador que le latigueaba las ancas." ${ }^{18}$ El otrora "gigante" líder de la División del Norte se había transformado en "pigmeo".

La Convención reaccionó ante los duros embates carrancistas, continuó su labor para unir a las distintas facciones, por lo que pedía confianza a los verdaderos revolucionarios para que aceptaran a la Convención como el verdadero centro aglutinador de la revolución, lejos de los personalismos. ${ }^{19} \mathrm{El}$ mensaje iba dirigido a los "equivocados" que ya debían haber reflexionado, pues seis meses habían transcurrido desde que la "soberanía convencionista se hacía presente en el país". ${ }^{20}$ Frías y los redactores de la prensa convencionista se esforzaron por encontrar un punto neutral, pero parece que no era el momento preciso para dirigir estos argumentos a sus correligionarios, pues la guerra sólo se detendría hasta que uno de los dos bandos fuese derrotado.

El Pueblo desacreditó de inmediato las líneas convencionistas asegurando que la Convención de Aguascalientes de 1914 "vomitó como un volcán en erupción, los detritus de todas las pasiones políticas, regándolas por el territorio nacional, como una inundación devastadora de hirviente lava", Villa y Zapata "el simio del norte y el troglodita del sur" impidieron en su momento que la revolución triunfase, pero Carranza se había "engrandecido" ante el nuevo brote reaccionario. La nota culminó asegurando que la justicia triunfaría y ello debía "devolver la vista a los ciegos como en

17 “El fracaso final”, El Pueblo, 17 de mayo de 1915, p. 3.

18 "El fracaso final", El Pueblo, 17 de mayo de 1915, p. 3.

${ }^{19}$ R. E. M., “Alta misión de la Asamblea Revolucionaria”, La Convención, 18 de mayo de 1915, p. 3.

${ }^{20}$ R. E. M., "Se derrumba el último obstáculo. A los revolucionarios por convicción", La Convención, 21 de mayo de 1915, p. 2. 
un espejismo de leyenda bíblica," ${ }^{21}$ haría ver su error a los convencionistas. Una vez más los argumentos convencionistas de unificación chocaron con la radicalidad propagandista carrancista.

\subsection{La batalla de Trinidad, la exageración y la distorsión noticiosa}

La lucha se mantenía en la prensa y en el campo de batalla. El diario convencionista aseguró el 19 de mayo de 1915 que la situación en el Bajío era "muy buena" para los hombres que estaban bajo el mando de Francisco Villa, el periódico insistió en no hacer caso a "la voz de la calle que todo lo deforma y abulta", la cual afirmaba que Obregón se había levantado con la victoria en León, La Convención publicó que la ciudad leonesa se encontraba en manos de la Convención y que la División del Norte se hallaba en Irapuato. ${ }^{22}$

La realidad era distinta. Tras la derrota en Celaya, Villa se retiró al norte y se reforzó con hombres de sus otros frentes (cancelando las ofensivas en Tampico y en el Noreste), además de reencontrarse con Felipe Ángeles, quien le aconsejó no pelear en León y resistir en Aguascalientes (Calzadíaz, 1967: t. II, 225). Mientras a las tropas de Obregón se anexaron las divisiones de Manuel M. Diéguez y Francisco Murguía (Barragán, 1985: t. II, 325). Pronto inició un nuevo enfrentamiento, uno de los más largos durante la revolución, pues se prolongó del 27 de abril al 5 de junio de 1915. El Ejército de Operaciones liderado por Obregón ocupó Irapuato, Silao y Guanajuato, con la mirada pusta en León. El 29 de abril comenzó un duelo continuo en la estación de Trinidad, nuevamente, con un planteamiento defensivo por parte de Obregón. Sin embargo, los ataques villistas se hicieron generales los días 22 y 23 de mayo, así como el 10 de junio. Los asaltos villistas desde la hacienda El Resplandor obligaron a Murguía y a Diéguez, quienes se encontraban en Silao y la estación Nápoles, a replegarse a la hacienda de Santa Ana del Conde en donde se hallaba Obregón (Barragán, 1985: t. II, 343).

Cuando el general Álvaro Obregón preparaba la nueva estrategia, sufrió el embate de una granada que le costó perder la extremidad superior derecha en la misma hacienda. El lugar que dejó vacante el "manco de Santa Ana del Conde", lo ocupó el general de brigada Benjamín G. Hill y el cinco de junio, tras llevar a cabo una junta el tres de junio en la que Murguía se mostró insistente en tomar una táctica ofensiva, se decidió atacar al enemigo. Con una estrategia envolvente, y la penetración de la caballería de

\footnotetext{
21 “Sección editorial. La austeridad frente al pillaje", El Pueblo, 23 de mayo de 1915, p. 3.

22 “La situación en el Bajío es muy buena”, La Convención, 19 de mayo de 1915, p. 1.
} 
Murguía por la retaguardia enemiga, colapsaron las líneas villistas y la población de León fue ocupada por los carrancistas. No obstante, la prensa no ensalzó en demasía la labor de Francisco Murguía. Para Barragán fue él el verdadero héroe de esta batalla: "Así como apunté con toda imparcialidad y honradez que sólo al genio militar del General Álvaro Obregón se debió la victoria de Celaya, quedando consagrado, desde entonces con el glorioso título de 'Héroe de Celaya', con idéntica solvencia moral, debe admitirse que al valor, a la pericia y a decisión del General Francisco Murguía se debió la brillante jornada de León." (Barragán, 1985: t. II, 354)

El Demócrata fue el primer diario que dio la noticia del triunfo del ejército carrancista sobre Villa, incluso publicó un "Extra" el domingo 6 de junio de 1915, en donde se describió el hecho de armas y se afirmó que Wtoda la artillería reaccionaria quedó en poder de los constitucionalistas." 23 El encabezado de El Pueblo del siguiente día, difundió la victoria de las huestes carrancistas en León: "El más importante triunfo alcanzado por las armas constitucionalistas." La nota exaltó la actuación de Obregón y sus hombres, quienes se batían "encarnizadamente" desde un mes atrás contra las fuerzas de Villa y Ángeles. Una vez más, el elemento mediante el que se buscó dar veracidad a los hechos de armas fue la inclusión de un telegrama de Obregón dirigido a Carranza fechado el cinco de junio de 1915 en donde dio cuenta de su triunfo. La contestación de Carranza fue anexada en el mismo número, que puso énfasis en el fragmento del discurso en donde el Primer Jefe aseguraba que la reacción estaba vencida desde Celaya y la inminente paz y restructuración social que ya se avecinaba. ${ }^{24}$

El editorial que fortaleció las aseveraciones de la primera plana no se hizo esperar y el ocho de junio se publicó una columna que llevó por título "la reacción ha recibido el golpe de gracia", en esta ocasión, "el tigre" -Pancho Villa- era descrito no sólo malherido, sino a punto de morir:

Doroteo Arango (a) Pancho Villa, como un tigre herido fugado de su jaula, va dejando a su paso una huella de sangre. El domador le persigue de cerca y la jaspeada bestia empieza a sentir el desvanecimiento de la fuerza que se fuga. La embestida fue colosal; pero Álvaro Obregón, el domador de fieras zapatovillistas, descargó muy fuerte sus látigos, tan fuerte que el tigre chihuahuense, espalda al domador, se fugó dejando en la arena a sus cachorros. ${ }^{25}$

\footnotetext{
23 “Los soldados del Gral. Obregón derrotaron a Fco. Villa”, El Demócrata, 6 de junio de 1915, p. 1.

24"Al felicitarlo ahora por el más importante triunfo con que ha cubierto usted de gloria a las armas constitucionalistas, puedo asegurar a usted que no está lejano el día en que restablezcamos la paz y el orden de la República, sírvase usted en aceptar mi más calurosa felicitación por el importante hecho de armas de ayer, y hacerla extensiva a los generales, jefes, oficiales y tropa por su heroico comportamiento. "La reacción ha recibido el golpe de gracia”, El Pueblo, 7 de junio de 1915, p. 1.

25 “Periodo de expectación”, El Pueblo, 8 de junio de 1915, p. 3.
} 
La conclusión era que ante la desaparición de la reacción, la legalidad constitucionalista estaba a punto de culminar la primera etapa de la obra revolucionaria. En la misma sintonía, se publicó la sección editorial "El orden y la paz en la República, pronto serán restablecidas", en donde se dio la razón a Carranza sobre que los ideales revolucionarios pronto comenzarían a verse reflejados en el país. ${ }^{26}$ "La primera parte de la revolución, la demoledora está hecha; Carranza es de hierro. La segunda parte la reconstructiva...está hecha también porque Carranza está allí." 27 La ciudad de León constituía entonces el inicio de una nueva época dentro de la propia lucha armada y así lo quería hacer notar la prensa carrancista.

El periódico carrancista incluso justificó la violencia utilizada por su facción, pues la empleada por la revolución constitucionalista era "necesaria y pasajera", se encargaría de destruir y arrasar los intereses contrarios a los verdaderos ideales "en el fondo va reconstruyendo y creando la nueva, la verdadera, la definitiva Patria Mexicana." 28 En pocas palabras el uso de la violencia y la guerra que se llevaba a cabo era una causa justa, se legitimaba por tener como objetivo la defensa del pueblo mexicano.

La prensa convencionista dio la noticia cinco días después que El Pueblo, siguiendo una vez más la estrategia de la omisión. Posiblemente la moral de sus hombres, y de su propio movimiento en la ciudad de México, se mostraba cada vez más disminuida, por lo que tuvieron que echar a andar su maquinaria propagandística en busca de crear su propia versión de los hechos. El sábado 12 de junio La Convención describió algo completamente distinto de los sucesos que se llevaron a cabo en León y sus alrededores, la primera plana aseguró: "El General Francisco Villa derrotó al Gral. disidente Álvaro Obregón" e incluso asentó que el líder carrancista había muerto después de perder el brazo en la hacienda de Santa Ana del Conde. Sin embargo, la tardanza para informar sobre el acontecimiento no sólo debe entenderse como una artimaña estratégica de los órganos informativos que mostraban preferencia por Pancho Villa, sino también como parte de un proceso de desinformación ocasionado por la propia guerra, durante la cual las informaciones podían cruzarse y provocar dificultades para conformar un relato único.

\footnotetext{
26 "El orden y la paz en la República, pronto serán restablecidas", El Pueblo, 8 de junio de 1915, p. 3.

27 “Después de León...el porvenir", El Pueblo, 10 de junio de 1915, p. 3.

28 "Las dos violencias", El Pueblo, 7 de junio de 1915, p. 3.
} 


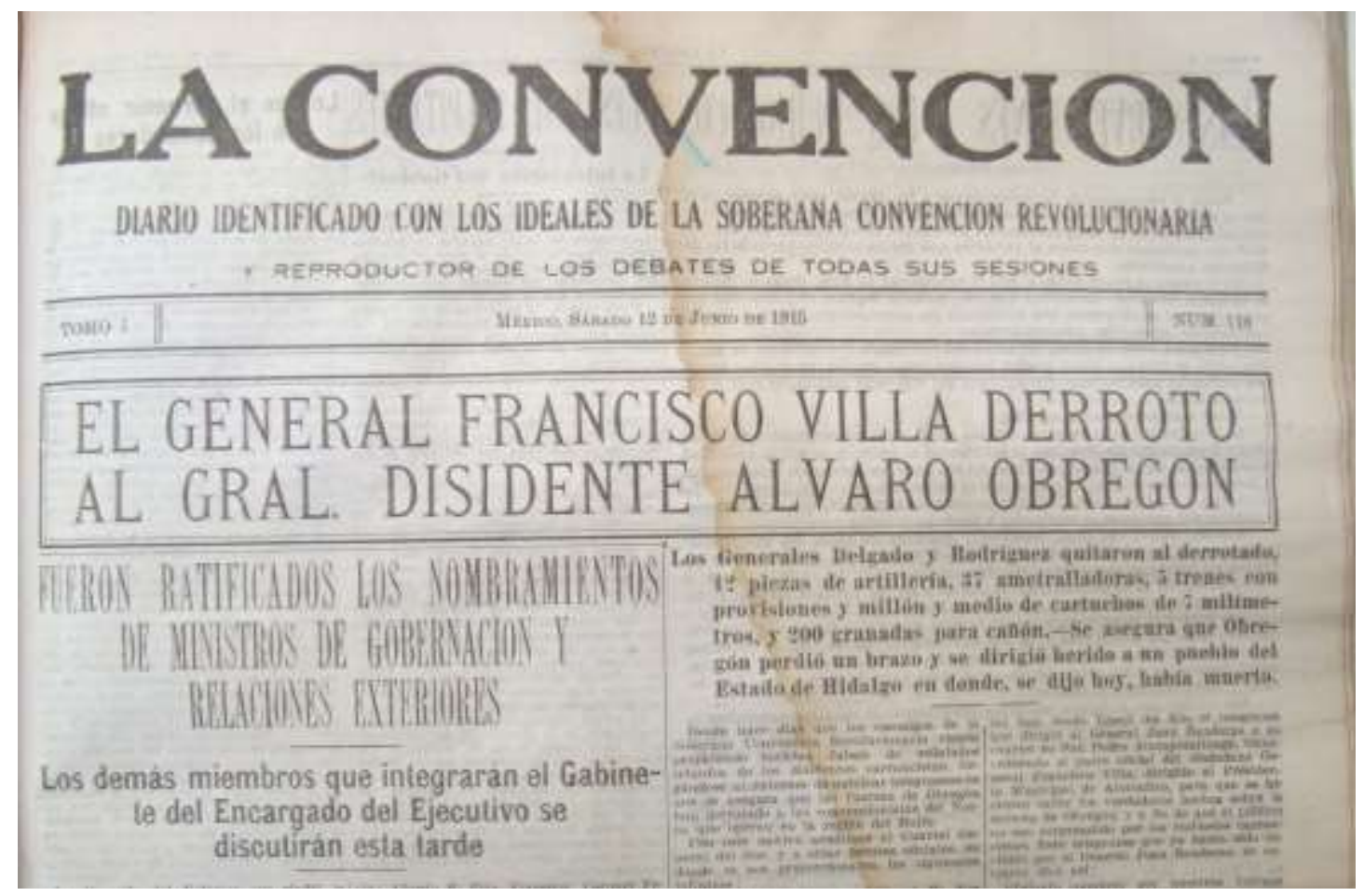

La Convención, 12 de junio de 1915, p. 1 (foto propia)

Asimismo, también es importante destacar que la contra-propaganda de la prensa provillista buscó refutar los diversos argumentos carrancistas, la mentira, en ocasiones, pudo funcionar para mantener las esperanzas de triunfar en el campo de batalla o, cuando menos, para no perder por completo la credibilidad ante la opinión pública. Un cronista de la época explica la desinformación que sufrió la ciudad de México a lo largo de las batallas entre villistas y obregonistas en el centro del país: "[...] jamás se ha vuelto a repetir el caso de que el pueblo capitalino permanezca tanto tiempo en la más completa ignorancia de los sucesos acaecidos en el resto de la Nación." (Ramírez, 1941: 416). Según este autor, sólo unas cuantas personas lograron enterarse oportunamente de las derrotas villistas en el Bajío, en gran medida por la "oficiosa" prensa convencionista que "tergiversó los hechos afirmando que el General Obregón había perecido en tales encuentros y que el cuerpo de operaciones a sus órdenes había sido completamente aniquilado; que el victorioso general Villa, [...] proseguiría su marcha triunfal hacia la capital después de haber dejado limpio de infidentes todo el Norte y Centro del país." (Ramírez, 1941: 411). Los hombres que hablaron por aquellos meses sobre la verdad de los hechos - asegura Ramírez Plancarte- fueron asesinados por las tropas zapatistas de la ciudad de México.

En resumen, la prensa convencionista nunca refirió la derrota del villismo en Celaya ni en Trinidad, seguramente por un par de factores: la falta de comunicación entre el Bajío y la ciudad de México, así como la propia labor propagandística que les impidió mostrar la "verdad". La primera página del 12 de junio de 1915, aseguró que desde 
varios días atrás los "disidentes carrancistas" estaban publicando noticias falsas en las cuales se aseguraba el triunfo de Obregón sobre Villa.

Su fuente de contraste para refutar la nota carrancista sobre el triunfo de los hombres del Primer Jefe, fue un informe del Cuartel General del Sur, según éste Villa había arribado a San Juan del Río tras un "soñado triunfo" frente a Obregón quien ya había muerto "en un pueblo del estado de Hidalgo." ${ }^{29}$ En el mismo número, se publicó el contenido del telegrama de Obregón en donde afirmó el triunfo a Carranza, la cual tacharon de "mentira carrancista" puesto que Villa se encontraba el día seis - fecha que apareció en el telegrama de Obregón- en Tepeji del Río con miras a ocupar la ciudad de México.

Ante las líneas vertidas en La Convención, El Pueblo respondió y puso en evidencia que "la mentira era una de las armas favoritas" de los hombres que seguían a Villa, en una nota asentaron que la "prensa reaccionaria" era incapaz de confesar sus derrotas, después de los triunfos de Obregón en Celaya, la prensa "contraria a los ideales de la Revolución", elevó la figura de Villa y pregonó una victoria 'colosal':

Obregón, decían los periódicos huerto-católicos, fue completamente despedazado. El campo de batalla quedó cubierto de reaccionarios constitucionalistas. [...] el éxito de Doroteo Arango, no tiene precedentes en la historia. Su triunfo ha venido a demostrar hasta la evidencia, que los prestigios de que goza son en verdad algo positivo, algo que puede definirse con esta sola frase: INVENCIBLE. Con tales informaciones, los rostros de los expatriados huerto-felicistas se iluminaron de intenso júbilo, Francisco Villa para ellos se había convertido en un superhombre, tan superhombre que en sus filas militaban viejos elementos esbirriescos del antiguo régimen. Pero afortunadamente, todos estos incendios de entusiasmo pasaron rápidos dejando después de tanta luminaria el puñado de cenizas de las desesperanzas. ${ }^{30}$

Los periódicos convencionistas insistían en los vínculos de Villa con los huertistas y otros contrarrevolucionarios. Los diarios carrancistas se mofaron de que Villa era el triunfador en Celaya. Villa el "indomable, el invencible, el gigante de la guerra" nunca podía perder, pero en esta ocasión ya era imposible seguir fingiendo falsos triunfos por parte de la Convención debido a que Doroteo Arango había perdido las batallas.

Dejando de lado lo vertido en la prensa puede afirmarse que los problemas en torno a la falta y defectos del parque de guerra, por los malos manejos del agente financiero de la División del Norte, Lázaro de la Garza, imposibilitaron a la División del Norte responder como lo hicieron en las batallas de 1914 (Torreón y Zacatecas,

\footnotetext{
29 “Las notas falsas del carrancismo", La Convención, 12 de junio de 1915, p. 1

30 "La nula sinceridad de la prensa reaccionaria", El Pueblo, 15 de junio de 1915, p. 5.
} 
principalmente) frente al ejército federal. La batalla de León fue mucho más reñida de lo que se ha divulgado, los villistas parecía que encontraban el triunfo el cinco de junio -y no se alejaban desalentados del campo de batalla-, pero diversos errores estratégicos dieron al traste con el intento villista, al final Pancho Villa tuvo que ordenar la retirada (Calzadíaz, 1967: t. II, 257-258).

Mientras El Pueblo lanzó importantes ataques contra la prensa convencionista, La Convención publicó secciones editoriales en donde se puso - una vez más - énfasis en la necesidad de unificar a los revolucionarios, pero en esta ocasión tomando como argumento un mensaje del presidente de Estados Unidos, Woodrow Wilson, de principios de junio, en el que buscaba solucionar los conflictos en México. La Convención insistió a lo largo de junio y julio que no se podía permitir que hubiese una nueva intervención extranjera en el país, por lo que continuó con la labor de fraternidad revolucionaria: "[...] todas las facciones revolucionarias que hicieron armas contra la Usurpación son idénticas y tienden a una inspiración común: el mejoramiento de las clases proletarias y el afianzamiento de las libertades para el pueblo, conquistadas en esta formidable conmoción sociológica." ${ }^{31} \mathrm{El} 1$ o de julio, La Convención aseguró que se había pactado un armisticio entre las facciones revolucionarias $^{32}$ y El Demócrata afirmó desde principios de junio que la nota de Wilson pronto reconocería al gobierno carrancista si elegía a los "mejores elementos" dentro del proyecto revolucionario. ${ }^{33}$

La guerra, para los convencionistas, debía llegar a su fin a través de medios pacíficos. Unos días más tarde, se publicó otro editorial en busca de demostrar que el llamado a la unión entre revolucionarios no representaba signos de debilidad. En esta ocasión, el argumento de la prensa se mostró un tanto desgastado e, incluso, desesperado ante las innumerables ocasiones que la Junta se había dirigido a sus "hermanos equivocados" en busca de la unificación:

por otra parte, los adversarios de la Convención han creído posiblemente que, si la Asamblea los llama a la concordia, a la unión digna para emprender labor honrada, es porque este grupo revolucionario no cuenta con elementos suficientes para llegar al triunfo por medio de la fuerza, ni tiene de su parte a la opinión pública que, aunque aparentemente sin poder ostensible, al fin y al cabo es la que decide de la suerte de los gobiernos. Cuando los enemigos se den cuenta de sus errores "pueden tornar al seno de la Convención, donde encontrarán hermanos que anhelan su regreso, que no desean privilegios ni

\footnotetext{
${ }^{31}$ R. E. M., "Por la Patria, por la revolución, por el deber", La Convención, 18 de junio de 1915, p. 2.

32 La Convención, 10 de julio de 1915, p. 1.

${ }^{33}$ El Demócrata, Veracruz, miércoles 2 de junio de 1915, p. 1.
} 
supremacías, y cuya sola aspiración es el triunfo definitivo de las ideas revolucionarias. $^{34}$

Empero, el 21 de junio de 1915 la prensa convencionista buscó nuevos argumentos para refutar las "verdades" carrancistas. El diario oficial de la Junta revolucionaria publicó una nota en la cual se aseguraba que el público sería informado diariamente de sobre las operaciones militares a través de boletines oficiales. Roque González Garza, encargado del poder Ejecutivo, en busca de mantener informada a la sociedad mandó a colocar un pizarrón en la fachada principal del Palacio Nacional en el que se propagaron las noticias "exactas" del resultado de los combates que se registraron diariamente en los diversos frentes. Ello debido a que "el Gobierno emanado de la S. Convención revolucionaria, no trata de ocultar la verdad de los acontecimientos, tal y como sean sin alterar nada, esto es, lo mismo se publicará las noticias de un triunfo como de una derrota." En la misma nota anexaron la opinión de un "enviado" que aseguraba que todas las versiones dadas a conocer hasta ese momento sobre lo que ocurría en el Bajío eran inexactas y los enemigos estaban "creando" a través de la prensa sus propios triunfos. "Estos han atacado a la división del Norte con gran vigor y al principio de la campaña en el centro obtuvieron algunas ventajas, que después han ido perdiendo. Agregaba el informante que la marcha de las fuerzas del Norte, hacia el Sur, es lenta porque así lo requieren las operaciones, pues bien conocida es la táctica del general Villa, de avanzar sin dejar enemigo a la retaguardia." ${ }^{35}$

Al día siguiente, El Renovador, periódico convencionista de reciente aparición y corta duración, insistió en el fallecimiento de Obregón: "ha quedado plenamente confirmada la muerte del general revolucionario Álvaro Obregón, que resultó gravemente herido de una granada disparada por la artillería del General Convencionista Felipe Ángeles." ${ }^{36}$ El diario afirmó en la misma nota, que la noticia de la muerte de Obregón había sido relatada con todos sus detalles en El Pueblo el 16 del mismo mes. La narración de la nota tuvo como fin asegurar que con la muerte de Obregón, Carranza jamás podría erigirse con la victoria frente a los ejércitos convencionistas.

La respuesta por parte de El Pueblo no se hizo esperar, dicho periódico contestó a los ataques en torno a la necesidad de unificar a la revolución. Para ello, de la misma forma en que lo venían señalando desde finales de 1914, era el ideal lo que le daba sentido a una guerra, no de tipo personalista, sino unida en torno al Primer Jefe. Para el carrancismo, el villismo no tenía, ni nunca lo había tenido, un ideal, sino sólo una

\footnotetext{
${ }^{34}$ R. E. M., "Bastante fuertes pero también razonables. Al llamar a la Unión no se exhibe debilidad, sino deseo vehemente de salvar la revolución", La Convención, 24 de junio de 1915, p.2.

35 “La verdad oficial sobre la actual situación política", La Convención, 21 de junio de 1915, p. 1.

36 "Se ha confirmado la muerte del Gral. Constitucionalista Álvaro Obregón", El Renovador, 22 de junio de 1915, p. 1.
} 
acumulación de factores diversos de fuerza, que "en los primeros trances han tenido que chocar en la necesidad de sobrepujarse los unos a los otros recurriendo esencialmente a combinaciones políticas, como la Convención de Aguascalientes, las negociaciones siempre inconstantes con Zapata, y demás medios de que quiso echarse mano para llegar a un triunfo que nunca podía llegar"37, Ángeles y Villa velaban por distintos ideales y nunca triunfarían, puesto que "carecían de honradez y, en cambio, tenían una gran ambición de poder".

En contraposición con ellos, Carranza había creado un ejército sin ambiciones, que no titubeaban, ni dudaban, pues todos se habían unido en la lucha por el ideal verdadero de la revolución. Al mismo tiempo, la prensa carrancista puso énfasis en la "inexistencia" de la alianza entre villistas y zapatistas, tanto en el ámbito de lo militar como en sus intentos por crear un proyecto de reformas sociales. La Convención aseguró que los hombres del norte y del sur aún se mantenían unidos y trabajando duro para derrotar a la reacción. No obstante, la prensa convencionista aceptó que existieron diferencias en algún momento, pero la propia inconsistencia de los hostiles carrancistas le habían dado nuevos bríos a sus filas. ${ }^{38}$

La derrota convencionista era evidente y la prensa adicta a dicho movimiento no podía seguir ocultándola. Los carrancistas llegaron a la ciudad de México y con ello la realidad fue revelada.

\subsection{El triunfo carrancista y el fin de la prensa convencionista}

Carranza publicó un manifiesto el 10 de junio de 1915, en él explicó la manera en que, después de cinco años de lucha armada, la Revolución estaba por llegar a su fin. Una vez vencido el enemigo, se podrían iniciar las reformas económicas, sociales y políticas que asegurarían la paz de la nación. Para el Primer Jefe ya se había iniciado el periodo preconstitucional durante el cual se llevaría a cabo lo necesario para, posteriormente, elegir a los nuevos encargados de los tres poderes de la Federación. ${ }^{39}$ Pese a la labor de la "reacción que tuvo como brazo armado a Villa", Carranza y su movimiento ya

\footnotetext{
37 “La unidad militar de la revolución", El Pueblo, 25 de junio de 1915, p. 3.

38 J. D. F., "La salud por la Guerra", La Convención, 25 de junio de 1915, p. 2.

39 “D. Venustiano Carranza. Jefe del Poder ejecutivo se dirige al pueblo mexicano", El Pueblo, 12 de junio de 1915, p. 1.
} 
tenía dominio sobre siete octavas partes del territorio mexicano, según el documento. ${ }^{40}$

El manifiesto mostró a Carranza como el triunfador absoluto, e iniciador de la nueva era de paz. El Pueblo en busca de dar a conocer los puntos de la propuesta del Primer Jefe, realizó una importante labor explicativa de cada uno de ellos en los números posteriores e invitó a sus lectores a examinar los postulados carrancistas. ${ }^{41}$

La Convención no mencionó la aparición del texto carrancista, no tenía forma de refutarlo e, incluso, las condiciones en que se publicaron sus diarios desde finales de junio, fueron por demás complejas. Sin embargo, El Combate y El Renovador, periódicos que representaron el último intento periodístico convencionista, criticaron la postura de Carranza y su "supuesta legalidad" alcanzada a partir de una lucha que estaba aún en definición. ${ }^{42}$ Ambos periódicos continuaron aceptando, en algunas ocasiones, al ejército de Pancho Villa como el brazo armado de la Convención. Todavía, el tres de julio, aseguró El Combate: "Son magníficas las condiciones de las fuerzas convencionistas del Norte." En la nota transcribieron el testimonio de un informante llegado desde Aguascalientes, quien aseguraba que la División del Norte había triunfado en todos los embates contra Obregón:

Son completamente falsas, dice nuestro informante, las versiones que se han hecho circular en esta capital respecto a que la División del Norte haya ido de fracaso en fracaso, si efectivamente ha encontrado de parte de las fuerzas constitucionalistas una tenaz resistencia, ha logrado recuperar las plazas que, como León, Irapuato y Silao, se hallan en poder del General Obregón. Por demás está decir, que es completamente absurda la noticia de que el general Villa se replegó con sus tropas al Norte de Aguascalientes. ${ }^{43}$

Siguiendo con el desarrollo de las campañas militares, las derrotas sufridas en Trinidad, obligaron a la División del Norte a concentrarse en Aguascalientes. Paralelamente, una columna comandada por los generales de la División del Norte Rodolfo Fierro y Canuto Reyes se separó del grueso del ejército villista y se encargó de aislar de su base de operaciones al general Obregón. Fierro fracasó en Lagos de Moreno, Jalisco, en un ataque contra las huestes carrancistas, no obstante, consiguió tomar el control de

\footnotetext{
40 "D. Venustiano Carranza. Jefe del Poder ejecutivo se dirige al pueblo mexicano", El Pueblo, 12 de junio de 1915, p. 3.

41 "De todos y de cada uno de los puntos tratados en el Manifiesto nos ocuparemos oportunamente; ellos merecen detallado examen y nuestro periódico dará a su estudio preferente atención. Entretanto, recomendamos a nuestros lectores la lectura de ese documento histórico y patriótico." "Lea usted el último manifiesto del señor Carranza", El Pueblo, 16 de junio de 1915, p. 3.

42 "El sol brilla: ciego el que no lo ve. Al margen de un manifiesto", El Combate, 23 de junio de 1915, p. 1.

43 "Son magníficas las condiciones de las fuerzas convencionistas del Norte", El Combate, 3 de julio de 1915, p. 1.
} 
León de los Aldamas y de ahí marchó al sur, en donde destruyó buena parte de la vía férrea y se concentró en Pachuca, hasta ese momento ocupada por el general Agustín Millán, quien tuvo que regresar a Ometusco ante el empuje de la columna villista (Barragán, 1985: t. II, 388-391). Estas acciones motivaron la salida de las tropas del general Pablo González de la ciudad de México, lugar al que recientemente había arribado. El triunfo de Fierro fue efímero y su columna regresó rumbo a Chihuahua una vez que había integrado a sus filas al ex Encargado del Poder Ejecutivo, Roque González Garza, quien había renunciado el 15 de junio de 1915.

Obregón - recuperado del percance de la destrucción de la vía férrea- decidió enfrentarse al enemigo en Aguascalientes. Después de iniciar su ataque por la barranca de Calvillo, los villistas "perdieron ímpetu" y Obregón, "casi como una copia" de los triunfos anteriores, lo derrotó el 10 de julio con la toma de la ciudad hidrocálida. El saldo fueron 1500 villistas caídos por 600 carrancistas, esta información nos la ofrecen tanto la prensa como la propia historiografía (Obregón, 1960: 407). El periodismo pro-Carraza ya no dio la misma difusión a estos hechos de armas, puesto que su interés se enfocó en la toma de la ciudad de México a lo largo de junio y julio.

Por su parte, la idea de la unificación revolucionaria trató de ser reflejada en los argumentos utilizados por la prensa convencionista, ante la toma de la ciudad de México por parte de Pablo González, repitiendo en diversas ocasiones que la División del Norte, con Pancho Villa al frente, se acercaba a la ciudad de México para recuperarla y unirse a Zapata.

Finalmente, resulta significativo echar un vistazo al número 37 de El Renovador. En su primera plana aseguró que "Con entusiastas vivas al general Fco. Villa fueron recibidos los hombres de la División del Norte. Los carrancistas entraron hasta el corazón de la ciudad pero fueron rechazados por fuerzas del Norte y del Sur." ${ }^{44}$ Sin embargo, Pablo González y sus hombres había llegado a la ciudad de México: el carrancismo había reconquistado la "antigua capital" y la prensa convencionista no volvió a ver la luz.

\section{Para cerrar}

La propaganda a través de la prensa se posicionó como otra arma dentro de las campañas militares en la Revolución mexicana, particularmente en la lucha armada que protagonizaron Pancho Villa y Álvaro Obregón en el Bajío.

\footnotetext{
44 "Con entusiastas vivas al general Fco. Villa fueron recibidos los hombres de la División del Norte", El Radical, 31 de julio de 1915, p. 1.
} 
Como se ha observado en este trabajo, carrancistas y convencionistas desarrollaron discursos para legitimar sus respectivos movimientos armados, sin embargo, pese a utilizar elementos propagandísticos similares, éstos distaron en efectividad y homogeneidad. En cuanto a la construcción del enemigo, los carrancistas siempre se mostraron enfáticos contra Pancho Villa y sus hombres más cercanos (Felipe Ángeles, regularmente), desarrollaron analogías ("tigre herido", "Atila del Norte", "Napoleón bandido"), pudieron fortalecer estos argumentos en buena medida porque el contexto bélico estaba de su lado. Mientras tanto, La Convención buscó la concordia y la reconciliación revolucionaria, demostrando argumentos endebles, reflejo de su compleja situación en los campos de batalla. Cuando las huestes carrancistas lideradas por Álvaro Obregón derrotaron a Villa en la estación de Trinidad, la prensa convencionista creó historias paralelas en donde Villa había triunfado y Obregón había fallecido; la mentira y la omisión fueron las últimas estrategias de los periódicos de la Convención. El triunfo carrancista marcó el fin de este combate periodístico, pues los órganos informativos de la Convención desaparecieron casi de inmediato. La uniformidad de la propaganda carrancista fue, sin lugar a dudas, una de sus principales virtudes.

¿Qué trascendencia tuvo la experiencia propagandística del periodo estudiado? La utilización de la prensa como arma propagandística en esta etapa marcó un hito en el desarrollo periodístico a corto, mediano y largo plazo. Los periódicos y periodistas de El Pueblo y El Demócrata se convirtieron en los defensores a ultranza del gobierno de Venustiano Carranza (1917-1920), aunque el primero desapareció en 1919 y mostró una fisura en el gabinete del coahuilense. El debilitamiento del gobierno de Carranza y la oposición periodística, representada principalmente por El Monitor Republicano que contaba en sus filas con hombres que habían adquirido experiencia entre 1909 y 1918 , fue fundamental para el ascenso al poder del grupo sonorense, conformado por Álvaro Obregón, Plutarco Elías Calles y Adolfo de la Huerta. La experiencia periodística de 1914-1915 fue fundamental para el desarrollo de las campañas electorales a través de la prensa en el periodo 1919-1920, como quedó plasmado en todos los periódicos de la capital mexicana.

La relación entre el poder y la prensa fue tensa en los primeros años de la década de los veinte. Su vínculo con las esferas gubernativas quedó fielmente marcada y consolidada con la creación del periódico del Partido Nacional Revolucionario (PNR, antecedente del PRM y del PRI) El Nacional, en 1929 y con el establecimiento de PIPSA (Productora e Importadora de Papel S. A.) fundada por el general Lázaro Cárdenas en 1935, cuyo objetivo era controlar el manejo y distribución del papel para las publicaciones periódicas.

Finalmente, a largo plazo, la versión plasmada en la propaganda carrancista de 1914 y 1915 definió la versión que las obras de actores de la época (Álvaro Obregón y Juan 
Barragán) y la historiografía dieron por sentada: los carrancistas ganaron de forma casi arrolladora frente a un ejército convencionista sin estrategias militares claras. La historia del periodo fue mucho más compleja, pero ello refleja el uso político de la propaganda para elaborar la historia de los vencedores: la Revolución se definió en las batallas de Celaya de abril de 1915. Con ello Obregón consolidó su figura de general invicto y mártir de la lucha armada, Villa quedó marcado como un personaje carismático, pero impulsivo e ineficaz en la guerra.

Con este texto queda demostrada la trascendencia de la prensa en el ámbito bélico, su uso en momentos de definición de una guerra y como punta de lanza para elaborar interpretaciones del pasado.

\section{Referencias bibliográficas}

ANDERSON, M. C. (2000): Pancho Villa's Revolution by headlines, Oklahoma, University of Oklahoma Press.

BARRAGÁN RODRÍGUEZ, J. (1985): Historia del Ejército y de la Revolución Constitucionalista, México, Instituto Nacional de Estudios Históricos de la Revolución Mexicana, tomo II.

BOBBIO, N. y MATEUCCI, N., (1982): Diccionario de Política, México, Siglo XXI, II v.

CALZADÍAZ, A. (1967): Hechos reales de la revolución mexicana, México, Patria, tomo II.

CHECA GODOY, A. (1993): Historia de la prensa en Iberoamérica, Sevilla, Alfar.

DOMENACH, J. M. (1962): La propaganda política, Buenos Aires, Editorial Universitaria.

FIGUEROA DAZA, J. E. (2010): "La propaganda política constitucionalista durante la Revolución Mexicana (diciembre de 1914-julio de 1915)", Sevilla, Universidad de Sevilla, Departamento de Comunicación, tesis de doctorado.

GARCIADIEGO, J. (1995): "La prensa durante la Revolución Mexicana", en Cano Andaluz, A. (coord.), Las publicaciones periódicas y la Historia de México, México, Universidad Nacional Autónoma de México, pp. 71-88.

GILLY, A. (comp.) (2008): Felipe Ángeles en la Revolución, México, Era, Consejo Nacional para la Cultura y las Artes.

HALL, L. B. (1985): Álvaro Obregón. Poder y Revolución en México, 1911-1920, México, Fondo de Cultura Económica. 
HUICl, A. (coord.) (2004): Los heraldos de acero. La propaganda de guerra y sus medios, Sevilla, Comunicación Social, Universidad de Sevilla.

KATZ, F. (2000): Pancho Villa, México, Ediciones Era, II tomos.

KNIGHT, A. (1996): La Revolución Mexicana: del Porfiriato al nuevo régimen constitucional, México, Grijalbo, II tomos.

MATUTE, Á. (1995): “Prensa, sociedad y política (1911-1916)", en Cano Andaluz, Aurora (coord.), Las publicaciones periódicas y la Historia de México, México, Universidad Nacional Autónoma de México, pp. 64-70.

OBREGÓN, Á. (1960), Ocho mil kilómetros en Campaña, México, Fondo de Cultura Económica.

PIZARROSO QUINTERO, A. (1990): Historia de la propaganda. Notas para un estudio de la propaganda política y de guerra, Madrid, Eudema.

- 1999): "La historia de la propaganda: una aproximación metodológica", en Historia y comunicación social, núm. 4, 1999, pp. 145-171.

QUIRK, R. E. (1962), La Revolución Mexicana, 1914-1915, México, Azteca.

RAMÍREZ PLANCARTE, F. (1941): La ciudad de México durante la Revolución Constitucionalista, México, Botas.

RUTHERFORD, J. (1973): La sociedad mexicana durante la revolución, México, El Caballito.

SALMERÓN, P. (2009): “Los historiadores y la guerra civil de 1915. Origen y persistencia de un canon historiográfico", en Historia Mexicana, vol. LVIII, núm. 232, abriljunio, pp. 1305-1368.

- (2015): 1915. México en guerra, México, Planeta.

SÁNCHEZ LAMEGO, M. Á. (1983): Historia militar de la revolución en la época de la Convención, México, Instituto Nacional de Estudios Históricos de la Revolución Mexicana.

\section{Hemerográficas}

El Radical

El Demócrata

El Pueblo. Diario de la mañana 
La Convención.

El Monitor

El Renovador

El Combate 